\title{
Multidimensional Apathy: Evidence from Neurodegenerative Disease
}

Ratko Radakovic ${ }^{12345^{*}}$ \& Sharon Abrahams ${ }^{245}$

${ }^{1}$ Faculty of Medicine and Health Sciences, University of East Anglia, UK

2 Human Cognitive Neuroscience, Psychology, University of Edinburgh, UK

${ }^{3}$ Alzheimer Scotland Dementia Research Centre, University of Edinburgh, UK

${ }^{4}$ Euan MacDonald Centre for Motor Neurone Disease Research, University of Edinburgh, UK

${ }^{5}$ Anne Rowling Regenerative Neurology Clinic, University of Edinburgh, UK

${ }^{*}$ Corresponding author: R. Radakovic, University of East Anglia, Queens Building, Norwich, NR4 7TJ Email addresses: r.radakovic@uea.ac.uk, radakovic.ratko@gmail.com Tel: +441603591441 


\section{Highlights:}

- The Dimensional Apathy Framework is a method for unifying the varied concepts of apathy

- The Dimensional Apathy Framework can be assessed by the Dimensional Apathy Scale - The prevalence of apathy in neurodegenerative diseases provides opportunity for research

- Patients with ALS, PD and AD show significantly different apathy profiles 


\begin{abstract}
Apathy is a demotivation syndrome common in neurodegenerative diseases and is fundamentally multidimensional in nature. Different methodologies have been used to identify and quantify these dimensions, which has resulted in multifarious concepts, ranging in the number and characteristics of apathy subtypes. This has created an ambiguity over the fundamental substructure of apathy. Here we review the multidimensional concepts of apathy and demonstrate that overlapping elements exist, pointing towards commonalities in apathy subtypes. These can be subsumed under a unified Dimensional Apathy Framework: a triadic structure of Initiation, Executive and Emotional apathy. Distinct cognitive processes may underlie these domains, while selfawareness interplays with all subtypes. Evidence from neurodegenerative diseases supports this distinction with differing apathy profiles in amyotrophic lateral sclerosis, Parkinson's disease and Alzheimer's disease.
\end{abstract}

\title{
Introduction
}


Apathy is defined as a lack of motivation towards goal-directed behaviour [1], and is a common symptom in neurodegenerative diseases, for review see [2]. Apathy is found in all types of dementia [3], while being prominent in Alzheimer's disease (AD) occurring in up to $92 \%$ of patients $[4,5,6]$ and vascular dementia [7]. In frontotemporal dementia (FTD) the presence of apathy can be used to support diagnosis [8], with a prevalence of $62 \%$ to $89 \%[9,10]$. An apathetic subtype of behavioural variant FTD has been proposed, with defining characteristics of apathy, inertia and avolition [11]. Apathy is also the most common type of behaviour change in amyotrophic lateral sclerosis (ALS), [12], with a prevalence of between $31 \%$ and $56 \%[13,14,15]$ and is a key feature of defining ALS with behavioural impairment as part of the ALS-frontotemporal spectrum disorder [16]. Up to 50\% of patients with Parkinson's Disease (PD) exhibit apathy $[17,18]$ and it is the most frequently reported neuropsychiatric symptom in those with PD dementia [19]. Apathy is also persistent and progressive across all stages of Huntington's disease [20,21], is a feature in progressive supranuclear palsy (PSP) [10, 22] and is also relatively common in multiple sclerosis [23]. The prevalence of this symptom in different neurodegenerative diseases provides opportunity to investigate the underlying subarchitecture of apathy.

It is now widely accepted that apathy is syndromic in nature [24**] and is composed of different dimensions/subtypes. As the concept of multidimensional apathy has evolved there has been discord with regards to the number and defining characteristics of these subtypes, with a need for refinement of definition and measurement [24**]. Here we review the past and emerging concepts of apathy in the study of neurodegenerative diseases and present a unified Dimensional Apathy Framework.

\section{Evolution of multidimensional apathy}

The evolution of models of apathy has been influenced by different research methodologies. Most have come from a psychometric approach, wherein subtypes are based on different descriptors and measurements of observed behaviour $[25,26,27,28,29,30]$. In contrast, others rely on experimental and/or a neurobiological approach, focusing on brain damage or imaging neuroanatomical correlates [31,32]. Table 1 shows a chronological summary of key multidimensional apathy concepts. 


\section{INSERT TABLE 1 HERE}

Despite varying definitions, most models retain a tripartite structure and many have emerged in parallel with specific measurement scales. The original conceptualisation of the cognitive, behavioural and emotional/affective subtypes [25] was based on observations of patients, prompting development of the initial diagnostic criteria for apathy [1] and also the Apathy Evaluation Scale (AES). This was the gold-standard, onedimensional instrument with a three factor substructure which when interpreted posthoc (through examination of face validity) were akin to cognitive, behavioural and emotional/affective dimensions. Research using the AES and the Apathy Scale (an abridged version of the AES) has shown a three factor substructure, albeit with variable characteristics (e.g. $[33,34,35])$. Other scales were developed including the Neuropsychiatric Inventory (NPI)- a behavioural screen for dementia which included a subscale to assess apathy [26], and The Apathy Inventory (AI) [27]. The latter signified a conceptual shift to the specific assessment of multidimensional apathy. The introduction of the Lille Apathy Rating Scale (LARS) [28], highlighted this further, albeit with four apathy domains instead of three. Starkstein and Leentjens [29] placed more of a focus on goal-directed elements of behaviour and cognition, and their view of emotional aspects of apathy acknowledged a conceptual distinction between a disorder of emotion or expression of emotions (affect) or a motivational disorder affecting emotional reactivity (flat affect and emotional unresponsiveness).

Levy and Dubois [31,32], similarly focused on motivation towards goal-directed behaviour but here they shifted to focus on the neuroanatomy of apathy. Different apathy subtypes were related to specific prefrontal-basal ganglia pathways. Damage to the medial prefrontal cortex, cognitive and limbic territories of the basal ganglia results in Auto-Activation apathy. Emotional-affective apathy is characterised by lesions to the orbito-medial prefrontal cortex and the limbic regions of the basal ganglia. Finally, the Cognitive subtype relates to dysfunction of the dorsolateral prefrontal cortex and cognitive territories of the basal ganglia. These have been supported by a review of apathy literature in PD [36]. Neuroanatomical models of apathy in neurodegenerative disease have emerged, with some focusing on a neurocognitive framework where apathy relates to disorders of goal-directed behaviours and is investigated through 
experimental paradigms [37]. Summatively other models or frameworks have shown the importance of frontal-prefrontal and parietal cortical-subcortical circuits with important clinical implications in neurodegenerative disease [36,38,39] akin to those proposed by Levy and Dubois $[31,32]$.

While the aforementioned apathy scales (AES, NPI, AI and LARS) and models have contributed to our understanding of apathy, there has been a lack of consensus in defining the characteristics and number of subtypes. A recent systematic review found that while many of the instruments were acceptable one-dimensional measures of apathy, they were not valid and reliable as an assessment of multidimensional apathy [40]. In light of this, we set out to develop a new unified apathy scale designed to assess separate subtypes within neurodegenerative diseases: Dimensional Apathy Scale (DAS) [30]. These dimensions were derived from comprehensive qualitative examination of 180 items from 12 existing apathy scales, where item themes were extracted and new items designed controlling for common measurement confounds of physical disability and depression. These new items were then applied to a normative sample of 311 participants, and subsequent factor analysis was performed to determine the substructure and finalise the DAS. Three clearly defined subtypes of apathy emerged as outlined in Table 1.

\section{Dimensional Apathy Framework}

When looking at the different models of apathy, commonalities clearly exist, which point towards a unified concept, the Dimensional Apathy Framework (shown in Figure 1). This is composed of demotivation associated with Initiation, Executive and Emotional apathy, measurable by the DAS.

\section{INSERT FIGURE 1 HERE}

A central theme throughout apathy models (see Table 1) is a deficit in Initiation which can be observed as a lack of self-generation of thoughts (and/or actions), reduced productivity and spontaneity. It is described throughout apathy models either as a part of a group of characteristics within a subtype [25,29], or as a specific subtype $[26,27,28,30,31,32]$. 
The next most commonly referred to domain relates to a deficit in cognitive processes typically subsumed under executive functions. Here participation and perseverance in tasks, daily activities and new routine formation are impaired [25,26,27]. A further expression of this type of apathy is as difficulty in forming new rules or strategies and shifting from behaviour sets, as well as error making [31,32]. These functions include a lack of motivation for organisation, attention and planning, as well as management of goals [30].

Emotional aspects of apathy are recognised explicitly in some subdivisions [25,26,27, 28,30,31,32]. Levy and Dubois [31,32] in their definition of Emotional-affective apathy include the most commonly used example of emotional blunting, where emotional reactivity is poor and short lived, with a focus on the individuals' lack of emotion and affect of their own and others behaviour [32]. This can further impact on the ability to evaluate both current or future behaviour. Figure 1 shows that while emotional apathy has many different facets, generally it encompasses an indifference or an emotional neutrality [30].

An additional factor that may interplay with apathy subtypes is self-awareness or concern. Previously, it has been observed as appearing within apathy assessments either at an item level [25] or within a description [29], as subtypes assessed by subscales [28] or over multiple domains, where self-reported apathy is disparate from informant -observed apathy [27]. Therefore, it could be proposed impaired selfawareness or concern likely spans over different subtypes, rather than existing as a standalone subtype, with more research needed to clarify this factor.

Finally, social elements of motivation or "social" apathy are also frequently subsumed under various apathy conceptualisations, which are attributed to different emotional/affective, as well as initiative, cognitive, 'self-awareness' and 'intellectual curiosity' subfactors or subtypes [25,26,27,28,30,31,32]. Stuss [41] describes "social" apathy as a metacognitive ability that mediates personal, social past and present information. Further to this, knowledge of behaviour or intention remains intact, but there is a lack of action in one's own self-interest. Upon this basis, it could therefore be 
speculated that "social" apathy is a culmination of emotional apathy in combination with other subtypes that is augmented by impairment of self-awareness (or metacognition), but further research should explore this complex interaction.

This type of apathy framework is supported by a model of executive functioning $[42,43]$, which is fractionated in to several processes. Energization relates to initiating and sustaining response, Monitoring and Task setting (unitarily called Executive functions) monitor and adjust performance, Behavioral/emotional self-regulation integrate emotional and social aspects of behaviour and Metacognition/Integration relate to higher order, coordinative processing between the other functions of the frontal lobes. These processes are linked to performance on specific neuropsychological tests, such as the verbal fluency task, Stroop task, simple and complex reaction time tasks, Wisconsin card sorting task, California verbal learning task amongst others $[42,43]$. There is a clear overlap between apathy subtypes and this executive functioning model $[31,32,41$, $42,43]$, suggesting that certain types of apathy may be associated with specific underlying cognitive processes (see Figure 2 for proposed overlap).

\section{INSERT FIGURE 2 HERE}

\section{Dimensional Apathy Framework: Evidence from Neurodegenerative Disease}

Recent research in ALS using the DAS has shown prominent Initiation apathy which occurs independent of other apathy subtypes in addition to motor disability $\left[44^{* *}, 45\right]$. Initiation apathy is also a symptom of $\mathrm{PD}$ and $\mathrm{AD}$ in combination with other apathy subtypes [46,47**] (See Figure 3 for a comparison of apathy profiles across ALS, PD and $\mathrm{AD}$ ), indicating the importance of this symptom across diseases. Further to this, a study using the AI observed that initiation apathy had specific neuroanatomical correlates in AD and PSP, where structural MRI showed a specific association with cortical atrophy of the anterior cingulate and ventrolateral orbitofrontal cortex with this type of apathy [48]. Related cognitive deficits fall under the associated concept of Energization (See Figure 2) $[42,43]$, thought to reflect an impairment in initiation and sustainment of response. ALS patients show difficulties with performance on motor independent reaction time tasks [49], but most notably verbal fluency deficits (impaired word generation). Verbal (predominantly letter) fluency are the most striking and 
characteristic deficit of this disease [12] and shown to be related to intrinsic response generation and independent of motor disability [50]. Our most recent work in ALS has demonstrated that Initiation apathy directly correlates with verbal fluency impairments, suggestive of shared underlying mechanisms of executive dysfunction and apathy subtypes $\left[51^{* *}\right]$.

In PD, using the DAS we have shown that in addition to Initiation apathy, individuals also displayed difficulty with motivation to plan, organise and attend to things, known as Executive apathy [46]. This type of apathy was also present in AD although these patients show a more global apathy profile with increased scores across all subtypes (see Figure 3) indicating the heterogeneity of apathy profiles across diseases [47**]. The study of PD has further illuminated the impact of apathy profiles, with the presence of Executive apathy significantly related to activities of daily living in PD [46], while an independent study using the DAS found that Executive apathy was associated with a reduced health related quality of life [52*]. However, these findings should be interpreted with caution as research has yet to consistently show Executive apathy in PD [53]. The association of Executive apathy with the Monitoring and Task setting component of Stuss' executive functioning model [42,43] suggests that the underpinnings of this type of apathy may be related to executive dysfunction, given that this is a common symptom of PD [54].

Research using the LARS showed Emotional apathy was elevated in FTD, as opposed to Action-initiation and Intellectual curiosity, when compared to AD [55*]. These clinical expressions of apathy were supported by positron emission tomography, showing apathy being associated with hypometabolism in the left lateral prefrontal, medial frontal and anterior cingulate, lateral orbitofrontal and anterior insular cortices in FTD, and right anterior cingulate in $\mathrm{AD}\left[55^{*}\right]$. A loss of sympathy and empathy is a defining characteristic of behavioural variant FTD and may be related to certain features of Emotional apathy. While this is yet to be robustly investigated in neurodegenerative disease, evidence in healthy adults seems to show associations between emotional apathy and empathy [56]. Furthermore emotional recognition and processing deficits in FTD are well documented [57]. In ALS, while Emotional apathy as measured by the DAS was not observed as characteristic of the whole group, it was found to associate with 
cognitive deficits in facial emotional recognition [51**]. In PD some studies using the DAS have reported Emotional apathy [53], while others have not [46]. This inconsistency could be due to patient heterogeneity or the fluctuating nature of dopamine, a key neurotransmitter relating to apathy that could affect manifestations of different subtypes, such as Emotional and Executive apathy e.g. [31,32,36]. Furthermore, in AD and PD, emotional apathy (assessed by the AI) had distinct neuroanatomical correlates, with emotional apathy correlating with atrophy of the left insular cortex [48].

Recent evidence has shown support for the interplay of self-awareness with apathy subtypes. Research using the LARS showed that FTD had a greater deficit in the Selfawareness domain of apathy compared to $\mathrm{AD}\left[55^{*}\right]$. Within $\mathrm{AD}$, discrepancy scores between self and informant ratings on the DAS have indicated a lack of self-awareness in patients, but which was observable to a larger magnitude in Executive and Initiation apathy $\left[47^{* *}\right]$. Apathy has been associated with lack of awareness of disease, cognitive or executive deficits (anosognosia) in dementia [58]. Levels of apathy increase together with a lack of awareness of cognitive task failure (error monitoring), while emotional reactions in response to experiences of illness or deficit (emotional reactivity) remain relatively intact [59], which could be supportive of Executive and Initiation apathy selfawareness deficits in dementia.

\section{INSERT FIGURE 3 HERE}

\section{Summary and Future Directions}

The concept of multidimensional apathy has evolved over the last 25 years, and while many concepts have been proposed, commonalities exist. These are unified under the Dimensional Apathy Framework, based on a traditional triadic structure of Initiation, Executive and Emotional Apathy, which may map on to underlying executive processes. While this substructure of apathy is at its base triadic, self-awareness interplays with the dimensions, which is of particular relevance to different dementias including AD and FTD, where lack of awareness (or anosognosia) is a prominent feature. The study of neurodegenerative disease has proved a valuable method to shed light on the subarchitecture of apathy, with a further need for confirmation of the substructure of 
demotivation using robust statistical techniques in larger samples of different neurodegenerative diseases and through brain imaging studies to establish neural correlates of different apathy subtypes. The development and use of newer more refined and comprehensive tools and techniques to detect different subtypes of apathy, such as the DAS [30] will allow these to be used in combination with neuroimaging techniques and neuropsychological assessment, so as to further our understanding of multidimensional apathy and how it impacts practical facets of living with disease.

\section{Conflicts of Interest Statement}

Nothing declared.

\section{Acknowledgements}

This work was supported by the Motor Neurone Disease Association and Motor Neurone Disease Scotland.

\section{References: \\ *of special interest ** Of outstanding interest}

[1] Marin RS: Apathy: a neuropsychiatric syndrome. J Neuropsychiatry Clin Neurosci 1991, 3:243-254.

[2] Chase TN: Apathy in neuropsychiatric disease: diagnosis, pathophysiology and treatment. Neurotox Res 2011, 19:266-278.

[3] Clarke DE, van Reekum R, Simard M, Streiner DL, Conn D, Cohen T, Freedman M: Apathy in dementia: clinical and sociodemographic correlates. J Neuropsychiatry Clin Neurosci 2008, 20(3):337-347.

[4] Mega MS, Cummings JL, Fiorello T, Gornbein J: The spectrum of behavioral changes in Alzheimer's disease. Neurology 1996, 46(1):130-135.

[5] Landes AM, Sperry SD, Strauss ME: Prevalence of apathy, dysphoria, and depression in relation to dementia severity in Alzheimer's disease. J Neuropsychiatry Clin Neurosci 2005, 17:342-349.

[6] Landes AM, Sperry SD, Strauss ME, Geldmacher DS: Apathy in Alzheimer's disease. J Am Geriatr Soc 2001, 49(12):1700-1707.

[7] Jonsson M, Edman Å, Lind K, Rolstad S, Sjögren M, Wallin A: Apathy is a prominent neuropsychiatric feature of radiological white-matter changes in patients with dementia. Int J Geriatr Psychiatry 2010, 25(6):588-595.

[8] Rascovsky K, Hodges JR, Knopman D, Mendez MF, Kramer JH, Neuhaus J, van Swieten JC, Seelaar H, Dopper EGP, Onyuje CU et al. Sensitivity of revised diagnostic criteria for the behavioural variant of frontotemporal dementia. Brain 2011, 134(9):2456-2477. 
[9] Mendez MF, Lauterbach EC, Sampson SM: An evidence-based review of the psychopathology of frontotemporal dementia: a report of the ANPA Committee on Research. J Neuropsychiatry Clin Neurosci 2008, 20(2):130-149.

[10] Bak TH, Crawford LM, Berrios G, Hodges JR: Behavioural symptoms in progressive supranuclear palsy and frontotemporal dementia. J Neurol Neurosurg Psychiatry 2010, 81(9):1057-1059.

[11] Snowden JS, Bathgate D, Varma A, Blackshaw A, Gibbons ZC, Neary D: Distinct behavioural profiles in frontotemporal dementia and semantic dementia. J Neurol Neurosurg Psychiatry 2001, 70(3):323-332.

[12] Goldstein LH, Abrahams S: Changes in cognition and behaviour in amyotrophic lateral sclerosis: nature of impairment and implications for assessment. Lancet Neurol 2013, 12(4):368-380.

[13] Grossman AB, Woolley-Levine S, Bradley WG, Miller RG: Detecting neurobehavioral changes in amyotrophic lateral sclerosis. Amyotroph Lateral Scler 2007, 8(1):56-61.

[14] Lillo P, Mioshi E, Zoing MC, Kiernan MC, Hodges JR: How common are behavioural changes in amyotrophic lateral sclerosis?. Amyotroph Lateral Scler 2011, 12(1):45-51.

[15] Witgert M, Salamone AR, Strutt AM, Jawaid A, Massman PJ, Bradshaw M, Mosnik D, Appel SH, Schulz PE: Frontal-lobe mediated behavioral dysfunction in amyotrophic lateral sclerosis. Eur J Neurol 2010, 17(1):103-110.

[16] Strong MJ, Abrahams S, Goldstein LH, Woolley S, Mclaughlin P, Snowden J, Mioshi E, Roberts-South A, Benatar M, Hortobágyi T et al. Amyotrophic lateral sclerosisfrontotemporal spectrum disorder (ALS-FTSD): Revised diagnostic criteria. Amyotroph Lateral Scler Front Degener 2017, 18(3-4):153-174.

[17] Kirsch-Darrow L, Fernandez HF, Marsiske M, Okun MS, Bowers D: Dissociating apathy and depression in Parkinson disease. Neurology 2006, 67(1):33-38.

[18] Pedersen KF, Larsen JP, Alves G, Aarsland D: Prevalence and clinical correlates of apathy in Parkinson's disease: a community-based study. Parkinsonism Relat Disord 2009, 15:295-299.

[19] Aarsland D, Brønnick K, Ehrt U, De Deyn PP, Tekin S, Emre M, Cummings JL: Neuropsychiatric symptoms in patients with Parkinson's disease and dementia:

frequency, profile and associated care giver stress. J Neurol Neurosurg Psychiatry 2007, 78(1):36-42.

[20] Thompson JC, Harris J, Sollom AC, Stopford CL, Howard E, Snowden JS, Craufurd D: Longitudinal evaluation of neuropsychiatric symptoms in Huntington's disease. $J$ Neuropsychiatry Clin Neurosci 2012, 24(1):53-60.

[21] van Duijn E, Kingma EM, van der Mast RC: Psychopathology in verified Huntington's disease gene carriers. J Neuropsychiatry Clin Neurosci 2007, 19(4):441448.

[22] Gerstenecker A, Duff K, Mast B, Litvan I: Behavioral abnormalities in progressive supranuclear palsy. Psychiatry Res 2013, 210(3):1205-1210.

[23] Figved N, Klevan G, Myhr KM, Glad S, Nyland H, Larsen JP, Harboe E, Omdal R, Aarsland D: Neuropsychiatric symptoms in patients with multiple sclerosis. Acta Psychiatr Scand 2005, 112(6):463-468.

[24] ** Lanctôt, K. L., Agüera-Ortiz, L., Brodaty, H., Francis, P. T., Geda, Y. E., Ismail, Z., Marshall GA, Mortby ME, Onyike CU et al. Apathy associated with neurocognitive disorders: recent progress and future directions. Alzheimers Dement 2017, 13(1):84100. 
A summative paper outlining the state, increased interest and progress of apathy research in the field. Notable observations include the need for further progress in defining apathy as a syndrome, particularly in refinement of its definition and measurement, with particular attention to subdomains.

[25] Marin RS, Biedrzycki RC, Firinciogullari S: Reliability and validity of the Apathy Evaluation Scale. Psychiatry Res 1991, 38(2):143-162.

[26] Cummings JL, Mega M, Gray K, Rosenberg-Thompson S, Carusi DA, Gornbein J: The Neuropsychiatric Inventory comprehensive assessment of psychopathology in dementia. Neurology 1994, 44(12):2308-2308.

[27] Robert PH, Clairet S, Benoit M, Koutaich J, Bertogliati C, Tible O, Caci H, Borg M, Brocker P, Bedoucha P: The Apathy Inventory: assessment of apathy and awareness in Alzheimer's disease, Parkinson's disease and mild cognitive impairment. Int J Geriatr Psychiatry 2002, 17:1099-1105.

[28] Sockeel P, Dujardin K, Devos D, Deneve C, Destée A, Defebvre L: The Lille apathy rating scale (LARS), a new instrument for detecting and quantifying apathy: validation in Parkinson's disease. J Neurol Neurosurg Psychiatry 2006, 77(5):579-584.

[29] Starkstein SE, Leentjens AF: The nosological position of apathy in clinical practice. J Neurol Neurosurg Psychiatry 2008, 79(10):1088-1092.

[30] Radakovic R, Abrahams S: Developing a new apathy measurement scale: Dimensional Apathy Scale. Psychiatry Res 2014, 219(3):658-663.

[31] Levy R: Apathy: a pathology of goal-directed behaviour. A new concept of the clinic and pathophysiology of apathy. Rev Neurol (Paris) 2012, 168(8):585-597.

[32] Levy R, Dubois B: Apathy and the functional anatomy of the prefrontal cortexbasal ganglia circuits. Cereb Cortex 2006, 16(7):916-928.

[33] Hsieh CJ, Chu H, Cheng JJS, Shen WW, Lin CC: Validation of apathy evaluation scale and assessment of severity of apathy in Alzheimer's disease. Clin Neurosci 2012, 66(3):227-234.

[34] Santangelo G, Barone P, Cuoco S, Raimo S, Pezzella D, Picillo M, Erro R, Moccia M, Pellecchia MT, Amboni M, Franco S, Grossi D, Trojano L, Vitale C: Apathy in untreated, de novo patients with Parkinson's disease: validation study of Apathy Evaluation Scale.J Neurol 2014, 261(12):2319-2328.

[35] Kay DB, Kirsch-Darrow L, Zahodne LB, Okun MS, Bowers D: Dimensions of apathy in Parkinson's disease: exploratory factor analysis of the apathy scale. $J$ Parkinsons Dis 2012, 2:161-166.

[36] Pagonabarraga J, Kulisevsky J, Strafella AP, Krack P: Apathy in Parkinson's disease: clinical features, neural substrates, diagnosis, and treatment. Lancet Neurol 2015, 14(5):518-531.

[37] Le Heron C, Apps, MAJ., \& Husain, M. (2017). The anatomy of apathy: a neurocognitive framework for amotivated behavior. Neuropsychologia 2017, doi:

10.1016/j.neuropsychologia.2017.07.003

[38] Ducharme S, Price, BH, Dickerson BC: Apathy: a neurocircuitry model based on frontotemporal dementia. J Neurol Neurosurg Psychiatry 2017, doi: 10.1136/jnnp2017-316277

[39] Moretti R, Signori R: Neural correlates for apathy: frontal-prefrontal and parietal cortical-subcortical circuits. Front Aging Neurosci 2016, doi:

10.3389/fnagi.2016.00289

[40] Radakovic R, Harley C, Abrahams S, Starr JM: A systematic review of the validity and reliability of apathy scales in neurodegenerative conditions. Int Psychogeriatr 2015, 27(6):903-923. 
[41] Stuss DT, van Reekum R, Murphy KJ: Differentiation of states and causes of apathy. In The Neuropsychology of Emotion. Edited by Borod JC. Oxford: Oxford University Press; 2000: 340-363.

[42] Stuss DT: Functions of the frontal lobes: relation to executive functions. J Int Neuropsychol Soc 2011, 17(5):759-765.

[43] Stuss DT, Alexander MP: Is there a dysexecutive syndrome?. Philos Trans R Soc B: Biol Sci 2007, 362(1481):901-915.

[44] ** Radakovic R, Stephenson L, Colville S, Swingler R, Chandran S, Abrahams S: Multidimensional apathy in ALS: validation of the Dimensional Apathy Scale.J Neurol Neurosurg Psychiatry 2016, 87(6):663-669.

This study determined the validity of a novel multidimensional apathy assessment (Dimensional Apathy Scale) in amyotrophic lateral sclerosis (ALS). The characteristic subtype impairment observed was Initiation apathy (lack of motivation for selfgeneration of thoughts) when compared to controls, which was found to occur independent of physical disability. This shows the specific apathy subtype profile in ALS.

[45] Santangelo G, Siciliano M, Trojano L, Femiano C, Monsurrò MR, Tedeschi G, Trojsi F: Apathy in amyotrophic lateral sclerosis: insights from Dimensional Apathy Scale. Amyotroph Lateral Scler Front Degener 2017, 18(5-6):434-442.

[46] Radakovic R, Davenport R, Starr JM, Abrahams S: Apathy dimensions in Parkinson's disease. Int J Geriatr Psychiatry 2018, 33(1):151-158.

[47] ** Radakovic R, Starr JM, Abrahams S. A Novel Assessment and Profiling of Multidimensional Apathy in Alzheimer's Disease. J Alzheimers Dis 2017, 60(1):57-67. This study determined the validity of the Dimensional Apathy Scale assessment in Alzheimer's disease (AD). Global apathy over all subtypes was observed in AD. Awareness of apathy subtypes (as determined by a discrepancy between self-ratings and informant/carer-ratings) was found to be impaired, specifically Executive apathy (lack of motivation for planning, organisation and attention) and Initiation apathy. [48] Stanton PN, Leigh RJ, Howard GJ, Barker RG: Brown Behavioural and emotional symptoms of apathy are associated with distinct patterns of brain atrophy in neurodegenerative disorders. J Neurol 2013, 260:2481-2490.

[49] Gillingham SM, Yunusova Y, Ganda A, Rogaeva E, Black SE, Stuss DT, Zinman L: Assessing cognitive functioning in ALS: A focus on frontal lobe processes. Amyotroph Lateral Scler Front Degener 2017, 18(3-4):182-192.

[50] Abrahams S, Leigh PN, Harvey A, Vythelingum GN, Grise D, Goldstein LH: Verbal fluency and executive dysfunction in amyotrophic lateral sclerosis (ALS).

Neuropsychologia 2000, 38(6):734-747.

[51] ** Radakovic R, Stephenson L, Newton J, Crockford C, Swingler R, Chandran S, Abrahams S: Multidimensional Apathy and Executive Dysfunction in Amyotrophic Lateral Sclerosis. Cortex 2017, 94:142-151.

This neuropsychological study looked to determine the overlap of cognitive dysfunction and apathy subtypes in amyotrophic lateral sclerosis (ALS). The results showed that the characteristic Initiation apathy was associated with deficits in internal response generation/energization (verbal fluency deficit) and also that Emotional apathy was associated with emotional recognition deficits. This is the first study to suggest shared underlying apathy subtype-cognitive mechanisms.

[52] * D'Iorio A, Vitale C, Piscopo F, Baiano C, Falanga AP, Longo K, Amboni M, Barone $\mathrm{P}$, Santangelo G: Impact of anxiety, apathy and reduced functional autonomy on 
perceived quality of life in Parkinson's disease. Parkinsonism Relat Disord 2017, doi: 10.1016/j.parkreldis.2017.08.003

This study determined the impact of apathy subtypes, assessed by the Dimensional Apathy Scale, and other non-motor symptoms in Parkinson's disease (PD). A lack of motivation for planning, organisation and attention (Executive apathy), as well as anxiety and functional autonomy, were potential determinants of poorer health related quality of life in PD.

[53] Santangelo G, D’Iorio A, Piscopo F, Cuoco S, Longo K, Amboni M, Baiano C, Tafuri D, Pellecchia MT, Barone P, Vitale, C: Assessment of apathy minimising the effect of motor dysfunctions in Parkinson's disease: a validation study of the dimensional apathy scale. Qual Life Res 2017, 26(9):2533-2540.

[54] Dirnberger G, Jahanshahi M: Executive dysfunction in Parkinson's disease: a review. J Neuropsychol 2013, 7(2):193-224.

[55] * Fernández-Matarrubia M, Matías-Guiu JA, Cabrera-Martín MN, Moreno-Ramos T, Valles-Salgado M, Carreras JL, Matías-Guiu J: Different apathy clinical profile and neural correlates in behavioral variant frontotemporal dementia and Alzheimer's disease. Int J Geriatr Psychiatry 2017, doi:10.1002/gps.4695

A study comparing the clinical apathy profile, using the Lille Apathy Rating Scale, of behavioural variant Frontotemporal dementia (bvFTD) and Alzheimer's disease (AD) patients. The results showed that bvFTD displayed greater emotional apathy and general lack of self-awareness than AD. Apathy was further shown to associate with different neuroanatomical substrates in each dementia group.

[56] Lockwood PL, Ang YS, Husain M, Crockett MJ: Individual differences in empathy are associated with apathy-motivation. Sci Rep 2017, doi: 10.1038/s41598-01717415-w

[57] Kumfor F, Piguet 0: Disturbance of emotion processing in frontotemporal dementia: a synthesis of cognitive and neuroimaging findings. Neuropsychol Rev 2012, 22(3):280-297.

[58] Starkstein SE, Brockman S, Bruce D, Petracca G: Anosognosia is a significant predictor of apathy in Alzheimer's disease. J Neuropsychiatry Clin Neurosci 2010, 22(4):378-383.

[59] Mograbi DC, Morris RG: On the relation among mood, apathy, and anosognosia in Alzheimer's disease. J Int Neuropsychol Soc 2014, 20(1):2-7. 
Table 1. Concepts of Multidimensional Apathy

\begin{tabular}{|c|c|c|}
\hline Author & Dimensions/Subtypes & Definition, symptoms/ deficits \\
\hline \multirow[t]{3}{*}{ Marin et al. [25] } & Behavioural & Decreased productivity, effortful actions, perseverance and lack of initiation behaviours. \\
\hline & Cognitive & $\begin{array}{l}\text { Decreased interest for learning new things, a lack of concern for oneself, inability to contribute value to } \\
\text { recreation, social situations or being productive with tasks. }\end{array}$ \\
\hline & Affective & $\begin{array}{l}\text { Emotional flatness, lack of responsiveness to emotionally charged events (both good and bad) and an } \\
\text { emotional blunting with unchanging affect }\end{array}$ \\
\hline \multirow[t]{3}{*}{ Cummings et al. [26] } & Initiative & Spontaneity is reduced e.g. does not start conversations or care about doing new things \\
\hline & Enthusiasm & Enthusiasm for and involvement in activities, interests, and household chores \\
\hline & Emotion & $\begin{array}{l}\text { Reduced affect and emotions when compared to the individual's usual self and reduced interest in family } \\
\text { members or friends }\end{array}$ \\
\hline \multirow[t]{3}{*}{ Robert et al. [27] } & Lack of initiative & Reduced conversation and decision making \\
\hline & Lack of interest & Reduced interest in hobbies, other people or their family members and their interests \\
\hline & Emotional blunting & Reduced affection and emotionally expression \\
\hline \multirow[t]{4}{*}{ Sockeel et al. [28] } & Intellectual curiosity & A lack of novelty seeking, interest and motivation along with a poor social life. \\
\hline & Action initiation & Unproductive in day-to-day life and lessened initiative \\
\hline & Self awareness & $\begin{array}{l}\text { "Meta-cognitive ability necessary to mediate information from a personal, social past and current history } \\
\text { with projections to the future" }\end{array}$ \\
\hline & Emotion & Emotional blunting of responses and diminished concern \\
\hline \multirow{3}{*}{$\begin{array}{l}\text { Starkstein and } \\
\text { Leetjens [29] }\end{array}$} & Goal-directed behaviour & A lack of energy of effort for daily activities and dependence on others for daily structuring \\
\hline & Goal-directed cognition & A lack of interest in new experiences or in learning new things and concern for one's own well being \\
\hline & $\begin{array}{l}\text { Goal-directed behaviour } \\
\text { "concomitants" }\end{array}$ & Flat affect and emotional unresponsiveness to positive or negative occurrences \\
\hline \multirow[t]{3}{*}{$\begin{array}{l}\text { Levy and Dubois } \\
\text { [31], Levy [32] }\end{array}$} & Auto-activation & $\begin{array}{l}\text { A lack of activity or initiation of goal-directed thoughts and actions, with a particular focus on self- } \\
\text { initiation. }\end{array}$ \\
\hline & Cognitive ('Cognitive inertia') & A lack of ability to expand on plans, organization or management of goals \\
\hline & Emotional affective & $\begin{array}{l}\text { Inability to associate behaviours with emotion or affect, which extends to the interpretation of affective } \\
\text { content and therefore experience of extreme affect. }\end{array}$ \\
\hline \multirow{3}{*}{$\begin{array}{l}\text { Radakovic \& } \\
\text { Abrahams [30] }\end{array}$} & Initiation & Lack of motivation for self-generation of thought \\
\hline & Executive & Lack of motivation for planning, organisation and attention \\
\hline & Emotional & Lack of emotional motivation, indifference or emotional neutrality \\
\hline
\end{tabular}


Behavioural [25], Initiative [26,27,37], Action initiation [28], Auto-activation [31,32], Initiation [30]

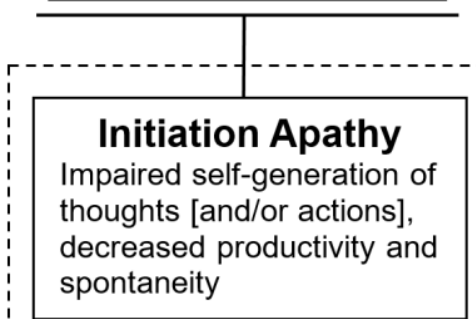

Cognitive [25], Enthusiasm [26], Lack of Interest [27], Intellectual

Curiosity [28], Goal-directed

behaviour and cognition [29]

Cognitive [31,32], Executive [30]

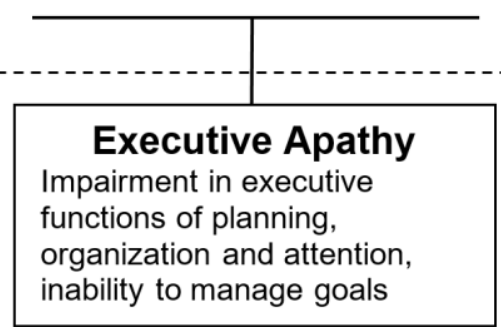

Affective [25], Emotional

$[25,26,28,30]$, Emotional Blunting

[27], Goal-directed

"concomitants" [29], Emotional affective [31,32]

\section{Emotional Apathy}

Affective flattening,

indifference, emotional

neutrality/blunting, emotional integration impairment

Figure 1. The Dimensional Apathy Framework - relation to apathy concepts from previous studies 


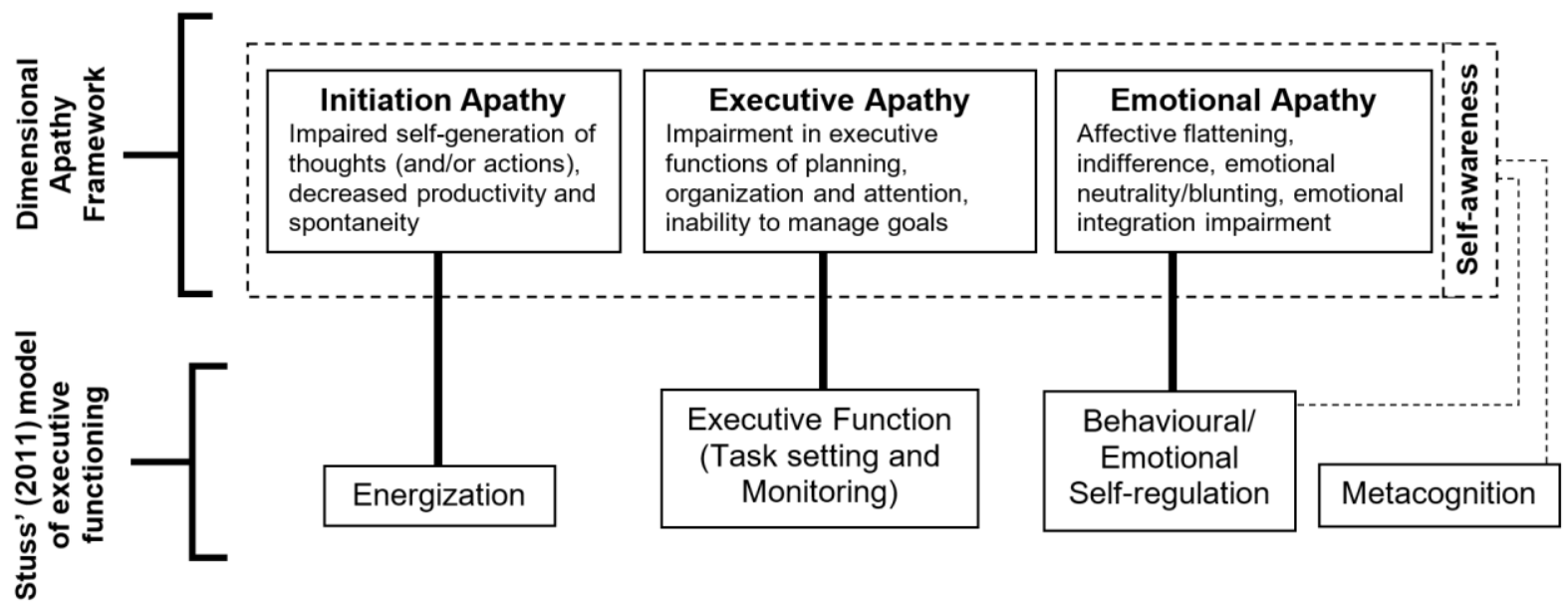

Figure 2. The Dimensional Apathy Framework: proposed overlap with Stuss (2011) $[42,43]$ model of executive functions 


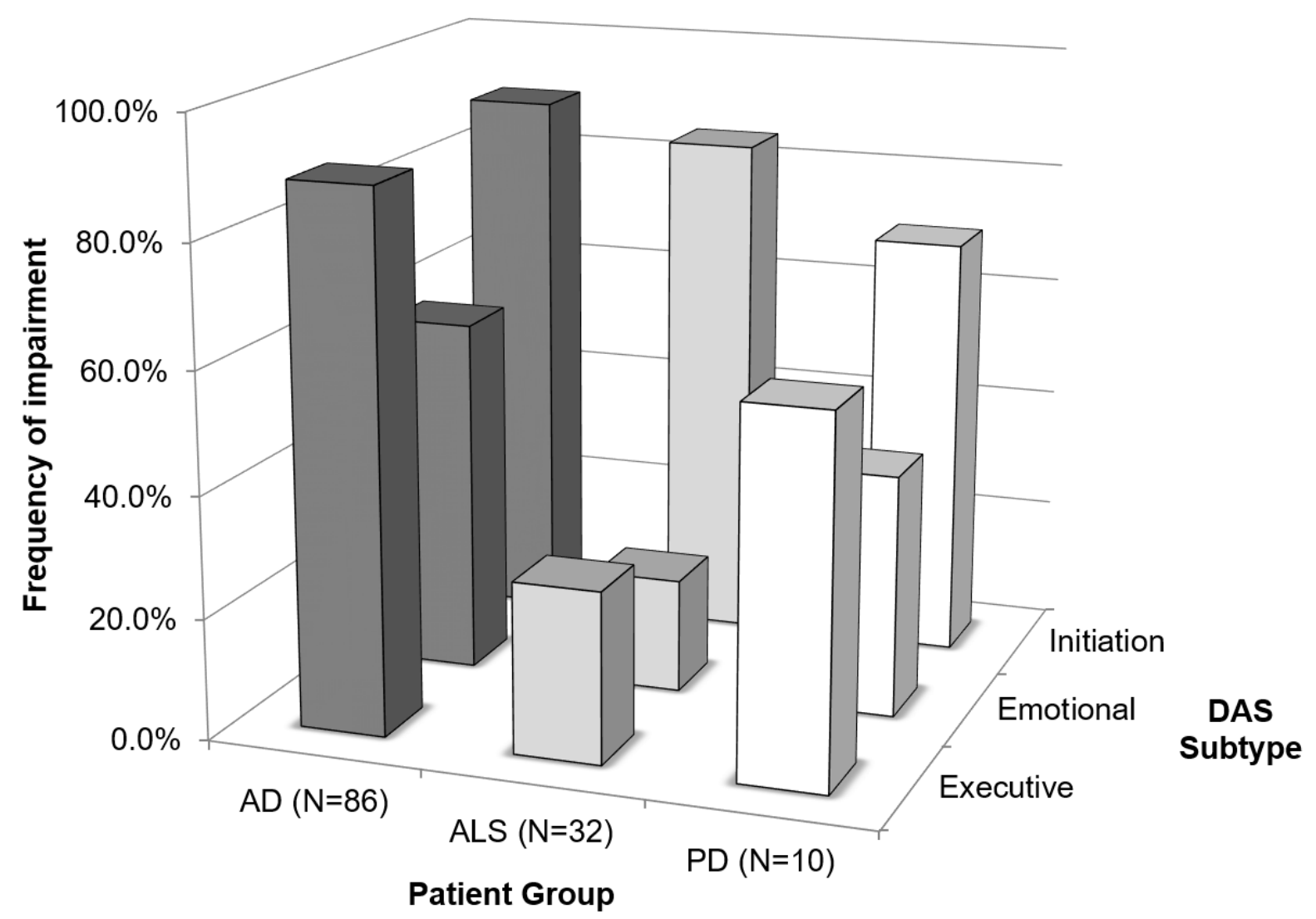

Figure 3. Frequency of impairment on each DAS Subtype in neurodegenerative disease patient groups (AD, ALS and PD) taken from $[44,46,47]$. Chi squared results show significant difference in apathy profiles, $\chi^{2}(12, N=128)=75.31, p<.001$ 